27 Norusis MJ. SPSS/PC+. Version 3.1. Chicago: SPSS Inc, 1989.

28 Armitage P, Berry G. Statistical methods in medical research. Oxford: Blackwell, 1987

29 Donaldson TJ. Pastoralism and drought. A case study of the Borana of southern Ethiopia [Dissertation]. Reading: University of Reading, 1986.

30 Bradley AK, Macfarlane SBJ, Moody JB, Gilles HM, Blacker JG, Musa BD. Malumfashi endemic diseases research project, XX. Demographic findings: mortality. Ann Trop Med Parasitol 1982;76:393-404.

31 Ethiopian Nutrition Institute. First round nutrition survey, October 1980. Addis Ababa: Ethiopian Nutrition Institute, undated.

32 Ethiopian Nutrition Institute, Vitamin A status of pre-school children in Ethiopia. An estimate of national prevalence. Addis Ababa: Ethiopian Nutrition Institute, undated.
33 Morley D, Woodland M, Martin WJ. Measles in Nigerian children. A study of the disease in west Africa, and its manifestations in England and othe countries during different epochs. $\mathcal{F}$ Hyg Camb 1963;61:113-34.

34 Rowland MG, Rowland SG, Cole TJ. Impact of infection on the growth of children from 0 to 2 years in an urban west African community. Am $\mathrm{f}$ Clin Nutr 1988;47:134-8.

35 De Waal A. Famine that kills. Darfur 1984-85. London: Save the Children 1988.

$36 \mathrm{Kloos} \mathrm{H}$. Health and resettlement in Ethiopia, with an emphasis on the 1984/85 resettement programme: a review. Eihiopian journal of ment Research 1989;11:61-94.

(Accepted 7 September 1990)

\title{
Long term survival after intensive care
}

\author{
S Ridley, R Jackson, J Findlay, P Wallace
}

\begin{abstract}
Objective-To examine the long term survival of critically ill patients admitted to an intensive therapy unit and to ascertain the effects of age, severity of illness, and diagnostic category at admission on survival.
\end{abstract}

Design-Retrospective observational study with prospectively gathered data on all patients admitted to the unit between June 1985 and July 1987 and followed up until 1 January 1989.

Setting-Regional intensive therapy unit.

Patients -513 Critically ill adult patients, 16 of whom were excluded because measurements on severity of illness scoring were not available.

Main outcome measures-Age, severity of illness (determined with the acute physiology and chronic health evaluation (APACHE) II score), and diag nostic category on admission; deaths in the unit; and long term survival after discharge. Details of the survivors were sent to the Registrar General for Scotland, who issued copies of death certificates for the patients who had died between discharge and 1 January 1989.

Results-Of 497 patients, $119(24 \%)$ died in the intensive therapy unit and $120(24 \%)$ after discharge, leaving $258(52 \%)$ who were still alive at two years. The median (APACHE II) score was 13 and about half of the patients were aged 55 years or more. A wide range of critical illnesses, except neurosurgical emergencies, were treated. Survival analysis showed that only 41 (34\%) of 122 patients with an APACHE II score of $\geqslant 20$ were alive at one year $(95 \%$ confidence interval 25 to 42 ) compared with $124(80 \%)$ of 155 patients with a score of $<10(73$ to 87$)$. Of the 144 patients aged 65 or more, only $68(47 \%)$ survived to one year (39 to 55) but $90(83 \%)$ of the 109 patients aged between 18 and 34 survived a similar period $(76$ to 71). Mortality was also related to diagnostic category; $71 \%$ of trauma victims survived to one year compared with only $41 \%$ of those admitted with gastrointestinal pathology. Univariate analysis of the results showed that age, severity of illness, and diagnosis were all predictors of long term survival. Multivariate analysis, however, showed that only age and severity of illness were independent prognostic factors.

Conclusions-Long term survival of patients treated in an intensive therapy unit is related to severity of illness and to age. The outcome from critical illness in the elderly population is poor

\section{Introduction}

Nunn et $a l^{1}$ and Searle ${ }^{2}$ described studies of the long term survival of patients who had been ventilated after intensive therapy. There has, however, been no recent study examining the long term survival of all patients discharged from a typical British intensive therapy unit. If guidelines for admission to such units are to be developed as recently proposed by the King's Fund Institute $^{3}$ then accurate data about the long term survival and the factors influencing such survival are needed. The aims of this study were, firstly, to study the survival of a large cohort of patients admitted to an intensive therapy unit and, secondly, to test the effects of age, diagnostic category, and severity of illness on survival.

\section{Patients and methods}

All patients admitted to our intensive therapy unit between June 1985 and July 1987 were included in the study. The severity of illness of each patient on admission was assessed with the acute physiology and chronic health evaluation II (APACHE II) scoring system (appendix). ${ }^{4}$ The patient's age, the diagnosis necessitating admission, and the outcome of intensive treatment were recorded.

Details of patients discharged from the intensive therapy unit, including date of birth and national health number, were reported to the central register for the NHS (office of the Registrar General for Scotland). The registrar issued copies of the death certificates of those patients who had died between the date of their discharge and 1 January 1989. Thus, depending on the date of admission, patients were followed up for between 18 and 42 months after discharge.

Statistical analysis-The effects of age, severity of illness, and diagnostic group at admission on long term outcome were initially examined in a univariate analysis to give Kaplan-Meier survival curves and by log rank tests. This was followed by a multivariate analysis based on the Cox proportional hazards model. A stepwise backwards elimination method was used, and the models were fitted using the biomedical data program statistical package.

\section{Results}

During the two year study period 513 adult patients were admitted to the intensive therapy unit. Sixteen patients were excluded from the study because the required measurements for APACHE II scoring were unavailable. The registrar could not trace 12 of the patients because they had either left Scotland or were living elsewhere in the United Kingdom at the time of their critical illness; these patients were assumed to be still alive.

Of the remaining 497 patients, $119(24 \%)$ died in the unit and $120(24 \%)$ died after discharge, leaving 258 $(52 \%)$ alive at 1 January 1989 . Table I shows the age distribution of the patients, severity of illness, and diagnostic categories. About half of the patients admitted were aged 55 years or more. The median APACHE II score for the whole group was 13 and the 
TABLE I-Distribution of patients' studied based on age, severity of illness (APACHE II score) on admission, and diagnostic category according to outcome at l Fanuary 1989. Values are numbers (percentages) of patients

\begin{tabular}{|c|c|c|c|c|}
\hline & \multicolumn{4}{|c|}{ Outcome } \\
\hline & $\begin{array}{l}\text { Died in intensive } \\
\text { therapy unit }(n=119)\end{array}$ & $\begin{array}{l}\text { Died after discharge } \\
\text { from unit }(n=120)\end{array}$ & $\begin{array}{l}\text { Long term survival } \\
\qquad(\mathrm{n}=258)\end{array}$ & Total $(n=497)$ \\
\hline \multicolumn{5}{|c|}{ Age group (years) } \\
\hline $18-34$ & $14(13)$ & 5 & $90(83)$ & 109 \\
\hline $35-44$ & $12(24)$ & $7(14)$ & $31(62)$ & 50 \\
\hline $45-54$ & $23(30)$ & $14(18)$ & $39(51)$ & 76 \\
\hline $55-64$ & $32(27)$ & $34(29)$ & $52(44)$ & 118 \\
\hline $65-74$ & $30(29)$ & $39(38)$ & $33(32)$ & 102 \\
\hline $75-84$ & $8(21)$ & $19(49)$ & $12(31)$ & 39 \\
\hline$\geqslant 85$ & 0 & $2(67)$ & $1(33)$ & 3 \\
\hline \multicolumn{5}{|c|}{ APACHE II score } \\
\hline $0-4$ & $2(5)$ & $1(3)$ & $37(93)$ & 40 \\
\hline $5-9$ & $5(5)$ & $28(25)$ & $77(70)$ & 110 \\
\hline $10-14$ & $21(17)$ & $32(25)$ & $74(58)$ & 127 \\
\hline $15-19$ & $31(32)$ & $30(31)$ & $37(38)$ & 98 \\
\hline $20-24$ & $26(37)$ & $20(29)$ & $24(34)$ & 70 \\
\hline $25-29$ & $25(63)$ & $7(18)$ & $8(20)$ & 40 \\
\hline$\geqslant 30$ & $9(75)$ & $2(17)$ & $1(8)$ & 12 \\
\hline \multicolumn{5}{|c|}{ Diagnostic category } \\
\hline \multicolumn{5}{|l|}{ Cardiovascular: } \\
\hline Hypovolaemia & $9(26)$ & $8(24)$ & $17(50)$ & 34 \\
\hline Sepsis & $22(50)$ & $6(14)$ & $16(36)$ & 44 \\
\hline Bleeding & $4(24)$ & $5(29)$ & $8(47)$ & 17 \\
\hline \multicolumn{5}{|l|}{ Respiratory failure: } \\
\hline Postoperative & $13(11)$ & $44(36)$ & $66(54)$ & 123 \\
\hline Primary & $13(28)$ & $16(34)$ & $18(38)$ & 47 \\
\hline Gastrointestinal & $18(36)$ & $16(32)$ & $16(32)$ & 50 \\
\hline Trauma & $12(20)$ & $6(9)$ & $43(70)$ & 61 \\
\hline Neurological & $3(43)$ & 0 & $4(57)$ & 7 \\
\hline Poisoning & $7(21)$ & $3(9)$ & $23(76)$ & 33 \\
\hline Cardiorespiratory arrest & $11(48)$ & $4(17)$ & $8(35)$ & 23 \\
\hline \multirow{2}{*}{$\begin{array}{l}\text { Others (including renal } \\
\text { failure) }\end{array}$} & & & & \\
\hline & $7(12)$ & $12(21)$ & $39(67)$ & 58 \\
\hline
\end{tabular}

scores on the 10th and 90th centiles were 5 and 25 respectively. The range of clinical categories was wide. The number of patients with neurological diagnoses was low, reflecting admission of such patients directly to a regional neurosurgical centre in a different hospital,

Figure 1 shows the survival curves from admission for the whole group of 497 patients stratified by age, APACHE II score, and diagnostic category at the time of admission respectively. In all three survival curves the immediate fall represents mortality in the intensive therapy unit and the more gradual decrease reflected death after discharge. Of the 144 patients aged 65 years or more, $68(47 \%)$ were alive at one year but only 55 $(38 \%)$ were alive at the end of two years. After an initial mortality in the intensive therapy unit of $13 \%(14 / 109)$ there were few deaths after discharge in patients aged $18-34$. At one year only $41(34 \%)$ of the 122 patients with an APACHE II score of $\geqslant 20$ on admission were alive compared with $120(80 \%)$ of the 150 patients admitted with a score of $<10$.

Figure 1c shows the mortality for each diagnostic category. Seventy per cent $(43 / 61)$ of trauma victims survived for one year, but only $41 \%$ of patients with a gastrointestinal diagnosis survived for a similar period.

Univariate analysis showed that age $\left(\chi^{2}=55 \cdot 1\right.$; $\mathrm{df}=3 ; \mathrm{p}<0.001)$, severity of illness $\left(\chi^{2}=90 \cdot 9 ; \mathrm{df}=2\right.$; $\mathrm{p}<0.001)$, and diagnosis $\left(\chi^{2}=24.0 ; \mathrm{df}=4 ; \mathrm{p}<0.001\right)$ were all predictors of long term survival. Multivariate analysis, however, showed that only age $\left(\chi^{2}=20 \cdot 1\right.$; $\mathrm{df}=1 ; \mathrm{p}<0.001)$ and severity of illness $\left(\chi^{2}=82 \cdot 1 ; \mathrm{df}=\right.$ $1 ; \mathrm{p}<0.001)$ were independent prognostic factors and that the broad diagnostic category was not $\left(\chi^{2}=7 \cdot 6\right.$; $\mathrm{df}=4 ; \mathrm{p}=0 \cdot 107)$. A simplified risk score describing the relation between the combined effects of age and APACHE II score on survival was derived by scaling and rounding the coefficients for Cox's proportional hazards model (table II), according to the relation simplified risk score $=($ age $)+($ APACHE score $\times 3)$. (The coefficient for age was approximated to the nearest whole number (actual value 3.31)). Figure 2 shows the survival curves stratified by the simplified risk score, and it illustrates the poor long term survival of patients with a score $>75$.

\section{Discussion}

The demographic details of the patients studied suggest that the variety and severity of conditions

TABLE II-Coefficients obtained from multivariate analysis

\begin{tabular}{lcc}
\hline Variable & Coefficient & $95 \%$ Confidence interval \\
\hline Age (years) & 0.022 & $0 \cdot 014-0.030$ \\
APACHE II score & 0.073 & $0 \cdot 059-0.087$ \\
\hline
\end{tabular}
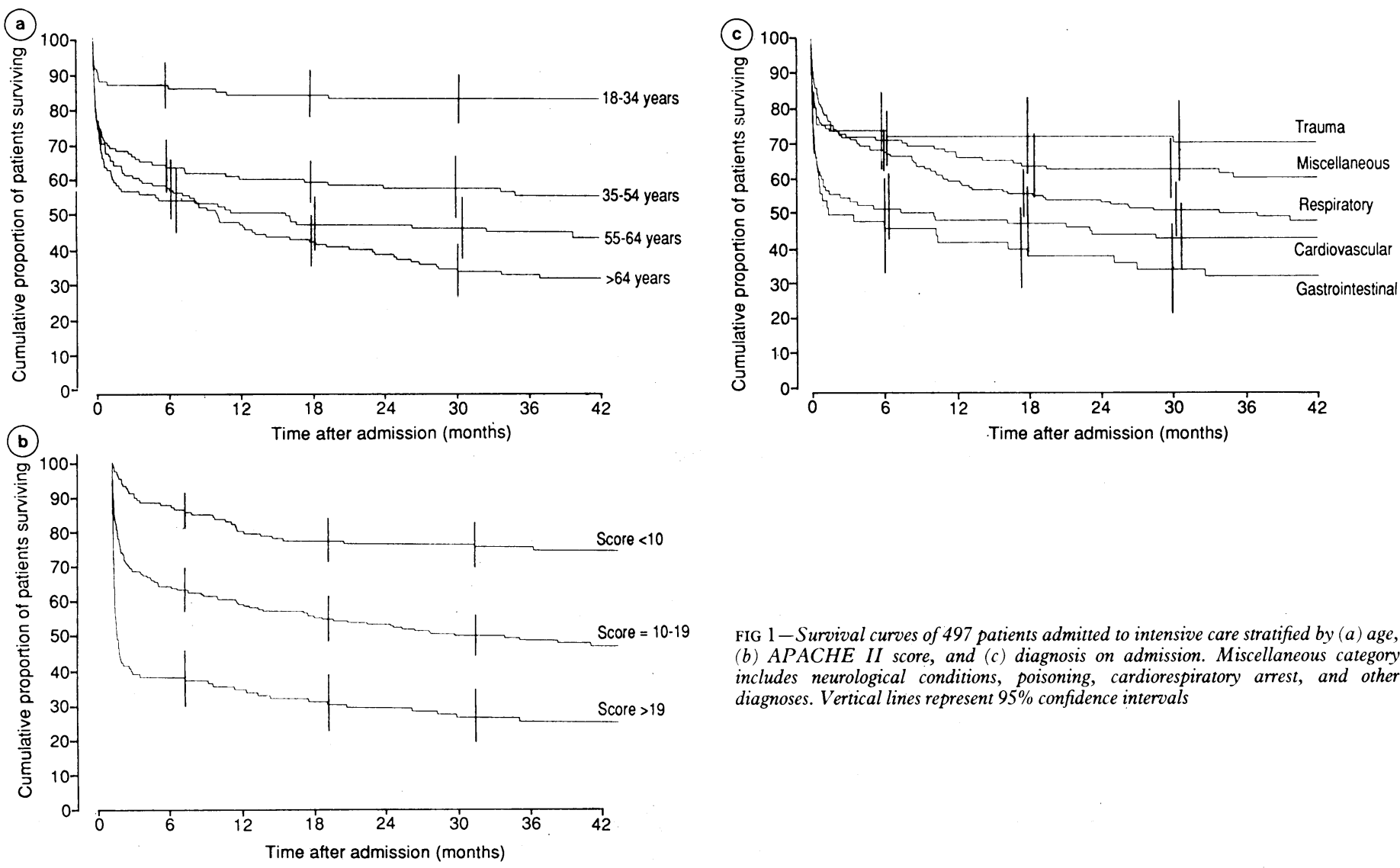

FIG 1-Survival curves of 497 patients admitted to intensive care stratified by (a) age, (b) APACHE II score, and (c) diagnosis on admission. Miscellaneous category includes neurological conditions, poisoning, cardiorespiratory arrest, and other diagnoses. Vertical lines represent $95 \%$ confidence intervals 


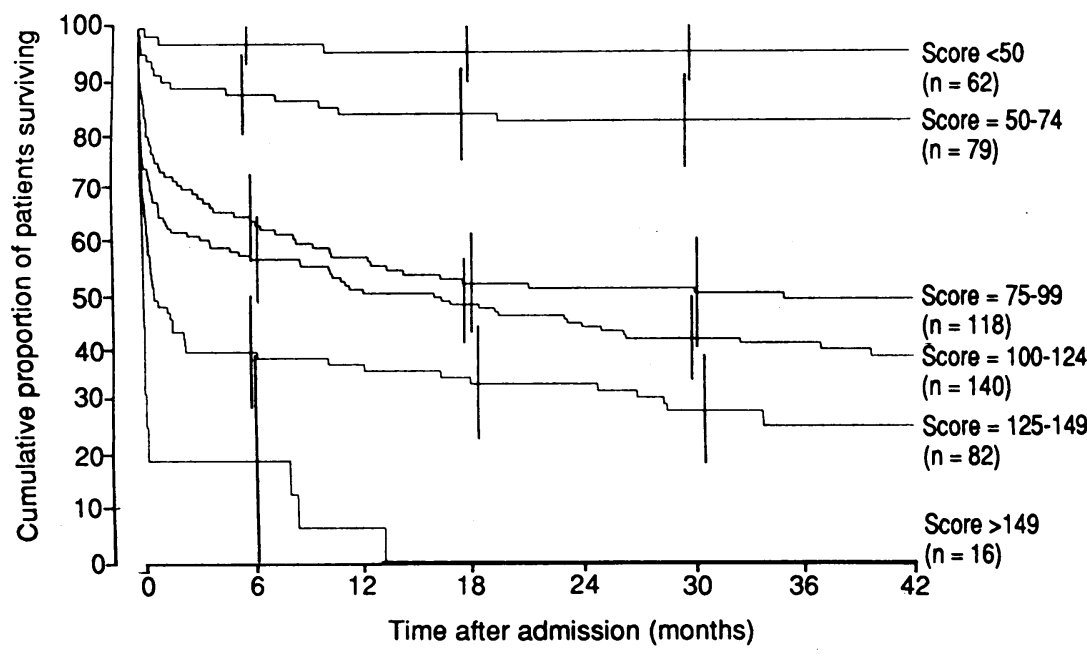

FIG 2-Survival curves stratified by simplified risk score calculated as (age) $+(A P A C H E I I$ score $\times 3$ ). Vertical lines represent $95 \%$ confidence intervals

treated at our hospital are a reasonable reflection of the workload of a typical general intensive therapy unit in the United Kingdom. Therefore, though these results may not be applied directly to other such units in the United Kingdom, they are probably more representative than findings from North America or Europe.

Zaren and Bergstrom in Sweden reported that health status one year after discharge remained unchanged or improved in $77 \%$ of survivors after intensive therapy. ${ }^{6}$ They also claimed that six months after discharge the survival of such patients paralleled that of an age matched general population. Our results, however, suggest that critical illness continues to shorten life expectancy for a considerable period after discharge, particularly in older patients, and therefore six month survival figures may be misleading. There are many possible reasons for this poorer outcome in elderly patients, ranging from residual functional disability and dysfunction of the organ systems to the unknown long term effects of severe prolonged physiological stress. It is, however, probable that survival rates after intensive care will be influenced by the general medical condition of the patient, something that might not be reflected in a simple classification of diagnosis at admission. If patients with chronic disease or age related conditions are concentrated in an intensive therapy unit then a high mortality may be expected after discharge. Careful selection of patients with acute reversible conditions will alter long term outcome, and differing degrees of patient selection between countries might explain the various reported survival rates.

There are many reports of poor long term outcome in older patients. In 1976 Cullen et al reported that only $19 \%$ of patients aged over 65 discharged from intensive therapy units were alive at one year. ${ }^{7}$ An update of these figures in 1984 failed to show any improvement. ${ }^{8}$ A study of medical intensive care (including cardiac, respiratory, gastrointestinal, and neurological diseases) concluded that age itself should not be a barrier to intensive therapy unit treatment as half the number of patients aged over 70 survived to one year. ${ }^{9}$ In another study of similar patients, however, only $27 \%$ were alive at one year. ${ }^{10} \mathrm{Clearly}$ some elderly patients benefit from the intensive monitoring and nursing care available in an intensive therapy unit. Our study confirmed, however, that age is an important factor when considering survival and should be given prominence in any model predicting long term outcome.

Several reports have shown a good correlation between physiological scores on admission to an intensive therapy unit and mortality in the unit. " et al reported that APACHE II score at admission was a good predictor of death in hospital but not of that after discharge when considered alone. ${ }^{12}$ Our results confirmed that the severity of illness at admission has a significant effect on long term outcome.

In certain specific circumstances such as cardiac arrest, ${ }^{13}$ head injury, ${ }^{14}$ non-traumatic coma, ${ }^{15}$ and haematological malignancies ${ }^{16}$ there are established guidelines for predicting outcome. Critical illness, however, is usually more complex, affecting simultaneous derangement of several organ systems. Guidelines for admission have been drawn up in the United States, ${ }^{17}$ but these are so broad that they offer no advice regarding individual patients. The APACHE system was originally designed to measure the severity of illness on admission, but it is often used to predict outcome for groups of patients. This scoring system does include up to six points allotted for age but our analysis implied that in this context age needs a higher weighting. The combination of age and APACHE II score to estimate the probability of long term survival might be useful when objectively assessing the appropriateness of intensive therapy unit facilities. Though accepting that any risk score will require prospective validation, such a score might help decision making by improving the predictive power of the APACHE II score or of age when used alone. Careful consideration should be given to the appropriateness of starting intensive therapy unit management in patients with high risk scores. This might allow a more reasoned approach when attempting to admit those patients in whom the chances of a reasonable duration and quality of survival merits the time, effort, and expense invested in their treatment. Risk scoring may also help in internal audit, when special attention may be given to the management of patients who die despite having a low score.

Diagnosis undoubtedly affects long term mortality. After studying over 5000 patients Knaus et al calculated risk factors for many individual diagnoses to improve prediction of mortality of the APACHE II score. ${ }^{4}$ In our study the reason for diagnostic category failing to reach significance was probably because of the broad categories used in the statistical analysis. To ensure an equal and reasonable subgroup size for statistical analysis the five categories listed in table I were used; the patients were allocated according to the diagnosis precipitating their admission to the intensive therapy unit and not according to coincidental or subsequent conditions. If this is accepted our study suggests that the effect of diagnosis on long term mortality as opposed to that in the intensive therapy unit might be less than the appreciable influences of APACHE II score and age.

Previous studies examining patients' quality of life after admission to an intensive therapy unit showed that it deteriorates after a critical illness. Searle reported that only $17 \%$ of survivors returned to their previously normal life, ${ }^{2}$ and Ridley and Wallace showed that in patients with a good quality of life before their critical illness, as assessed by Rosser disability categories, this decreased significantly after a critical illness. ${ }^{18}$ If there are minimal gains in quality of life long term survival may be of paramount importance to justify starting intensive therapy unit management and measuring its effectiveness.

In conclusion, this study indicates that long term survival after intensive therapy unit treatment is significantly related to the severity of illness on admission and to age: The outcome in patients aged over 65 is poor with only $38 \%$ alive at two years. Although further work to refine and validate predictive methods is required before accurate estimates of outcome may be applied to individual patients, risk scoring obtained by combining age and severity of illness scores might be useful when attempting to work out a reasoned admission policy. 
We thank Dr Gordon Murray for his supervision of the statistical analysis.

\section{Appendix}

The APACHE II score is a simplified form of the original APACHE system, which attempts to measure reliably and objectively the severity of disease so that a patient's immediate prognosis may be estimated. The system is based on the principle that the outcome from an acute illness relates to the degree of disturbance in the physiology of the main organ systems, to the patient's age, and to the presence or absence of pre-existing severe chronic health problems.

The main part of this scoring system is an acute physiology score comprising 12 readily available physiological measurements. The value of each measure is given a weight varying from 0 to 12 depending on its deviation from a predetermined normal range and on its relative importance to patient outcome as determined by an expert multidisciplinary pane and by a review of past experience. The resulting acute physiology score varies from 0 to 45 ; a higher score representing a greater degree of physiological derangement and a higher risk of death. To estimate prognosis this score is combined with additional points for advanced age and preexisting chronic health problems relating to the hepatic, cardiovascular, respiratory, renal, and immune systems to form the full APACHE II score. This score has a theoretical range of 0 to 71 , but an observed range of 0 to 50 is more probable. The higher the score the greater the patient's acute risk of death.

1 Nunn JF, Milledge JS, Singaraya J. Survival of patients ventilated in a intensive therapy unit. $B M \mathcal{F}$ 1979;279:1525-7.
2 Searle JS. The outcome of mechanical ventilation: report of a five year study Ann R Coll Surg Engl 1985;67:187-9.

Working Party, King Edward's Hospital Fund. Intensive care services. orking Party, King Edwarthesia 1989;44:428-31.
Anaest

4 Knaus WA, Draper EA, Wagner DP, Zimmerman JE. APACHE II: a severity of disease classification system. Crit Care Med 1985;13:818-29.

5 Dixon WJ, Brown MB, Engelman L, et al. Biomedical data program statistical software. Berkeley, California: University of California Press, 1985

6 Zaren B, Bergstrom R. Survival compared to the general population and changes in health status among intensive care patients. Acta Anaesthesio Scand 1989;33:6-12.

7 Cullen DJ, Ferrara LC, Briggs BA, Walker PF, Gilbert J. Survival, hospitalisation charges, and follow up results in critically ill patients. $N E n g$ f Med 1976;294:982-7.

8 Cullen CJ, Keene R, Waternaux C, et al. Results, charges, and benefits for critically ill patients. Update 1983. Crit Care Med 1984;12:102-6.

9 Fedullo AJ, Swinburne AJ. Relationship of patient age to cost and survival in a medical insive care un Crit Care Med 1983;11:155-9.

10 Witek TJ, Schachter EN, Dean NL, Beck GJ. Mechanically assisted ventilation in a community hospital. Arch Intern Med 1985;145:235-9.

11 Cullen DJ, Keene R, Waternaux C, Paterson H. Objective quantitative measurement of illness in critically ill patients. Crit Care Med 1984;12: measure

12 Sage WM, Rosenthal MH, Silverman JF. Is intensive care worth it? - An assessment of input and outcome for the critically ill. Crit Care Med 1986;14:777-82.

13 Beddel SE, Delbanco TL, Cook E, Epstein EH. Survival after cardiopulmonary resuscitation in hospital. N Engl f Med 1983;309:569-76.

14 Jennett B, Teasdale G, Braakman R, et al. Prognosis of patients with severe head injury. Neurosurgery 1979;4:283-9.

15 Levy DE, Bates D, Caronna J, et al. Prognosis in non-traumatic coma. Ann Intern Med 1981;94:293-301.

16 Lloyd-Thomas AR, Wright IH, Lister TA, Hinds CJ. Prognosis of patients receiving intensive care for lifethreatening medical complications of receiving intensive care for lifethreatening medic

17 Task Force on Guidelines, Society of Critical Care Medicine. Recommendations for intensive care unit admission and discharge criteria. Crit Care Med 1988;16:807-8.

18 Ridley SA, Wallace PGM. Quality of life after intensive care. Anaesthesia 1990;45:808-13.

(Accepted 31 August 1990)

\title{
Sexual transmission of hepatitis $C$ virus and its relation with hepatitis B virus and HIV
}

\author{
J Tor, J M Llibre, M Carbonell, R Muga, A Ribera, V Soriano, B Clotet, M Sabriá, M Foz
}

\section{Abstract}

Objective-To determine the extent of transmission of hepatitis $C$ virus in sexual partners of intravenous drug misusers and to examine the relation between the prevalences of HIV, hepatitis B virus, and hepatitis $C$ virus infections in homosexual men and intravenous drug misusers and their sexual partners.

Design-Serum samples collected between 1984 and 1988 were tested for hepatitis $B$ virus markers and antibodies against hepatitis $C$ virus by enzyme linked immunosorbent assay (ELISA) and for HIV antibody by enzyme immune analysis and western blotting.

Setting - Large referral university hospital with an external AIDS clinic in the metropolitan area of Barcelona, Spain.

Subjects-243 Intravenous drug misusers, 143 of their regular heterosexual partners, and 105 homosexual men.

Main outcome measures-Prevalences of hepatitis $C$ virus, hepatitis B virus, and HIV infections.

Results - In all, 178 of the $243(73 \%)$ intravenous drug misusers, 16 out of $143(11 \%)$ of their partners, and 17 of the $105(16 \%)$ homosexual men had antibodies against hepatitis $\mathrm{C}$ virus. The presence of hepatitis $C$ virus infection was unrelated to sex, age, the presence of HIV or hepatitis B virus infections, or the Centers for Disease Control stage of HIV. In sexual partners of intravenous drug misusers there were strong correlations between the presence of hepatitis $C$ virus infection and that of HIV $(p=0.001)$ and hepatitis $B$ virus $(p=0.013)$ infections.

Conclusions-Intravenous drug misusers have a high risk of acquiring hepatitis $\mathbf{C}$ virus, hepatitis $B$ virus, and HIV infections, but the presence of hepatitis $\mathrm{C}$ virus infection seems to be unrelated to the presence of the other two viruses. Homosexual men have a high prevalence of HIV and hepatitis B virus infections with a low prevalence of hepatitis $C$ virus infection, the presence of which is not related to that of the other two infections. Conversely, heterosexual partners of intravenous drug misusers have low prevalences of the three virus infections, but the presence of hepatitis $C$ virus infection correlates significantly with the presence of HIV and hepatitis $B$ infections. The rate of sexual transmission of hepatitis $C$ virus seems to be low, even in partners of people known to be seropositive for this virus.

\section{Introduction}

A complementary DNA clone derived from a bloodborne non-A non- $\mathrm{B}$ hepatitis virus genome that has been named hepatitis $C$ virus has been isolated, ${ }^{1}$ and a specific recombinant based immunoassay to capture circulating antibodies against hepatitis $C$ virus is now available. ${ }^{2}$ This virus has been shown to be the virus present in most $(79-85 \%)$ patients with non-A non-B hepatitis after transfusion, and $60-78 \%$ of haemophiliacs, $48-70 \%$ of intravenous drug misusers, and $20 \%$ of patients undergoing haemodialysis have antibodies against it. ${ }^{3-6}$ These antibodies have, however, also been found in patients with chronic hepatitis, cirrhosis, or hepatocellular carcinoma who have not had a blood transfusion. ${ }^{78}$ This epidemiological evidence is worrying, and other overriding risk factors that are not bloodborne or transmission routes could be involved in patients who have not undergone transfusion. The transmission of hepatitis $\mathrm{C}$ virus through sexual contact is of concern and preliminary data are 